\title{
Neonatal Peripheral Immune Challenge Activates Microglia and Inhibits Neurogenesis in the Developing Murine Hippocampus
}

\author{
Peter L.P. Smith ${ }^{a}$ Henrik Hagberg ${ }^{a, c}$ Andrew S. Naylor ${ }^{a, b}$ Carina Mallard $^{a}$ \\ anstitute of Neuroscience and Physiology, Sahlgrenska Academy, and ${ }^{b}$ Centre of Brain Research and Rehabilitation, \\ Institute of Neuroscience and Physiology, University of Gothenburg, Gothenburg, Sweden; ${ }^{\mathrm{C}}$ Centre for the \\ Developing Brain, King's College, London, UK
}

\section{Key Words}

Microglial phenotype $\cdot$ Lipopolysaccharide $\cdot$ Hippocampal development $\cdot$ M1 $\cdot$ M2 $\cdot$ Microglia proliferation $\cdot$ Microglia activation $\cdot$ Lys-EGFP-ki mice

\begin{abstract}
The early postnatal period represents an important window in rodent hippocampal development with peak hilar neurogenesis and widespread microgliogenesis occurring in the first week of life. Inflammation occurring during this period may negatively influence development, potentially facilitating or increasing susceptibility to later-life pathology. We administered the Gram-negative bacterial coat protein lipopolysaccharide (LPS) systemically at postnatal day $5(1 \mathrm{mg} /$ $\mathrm{kg}$ i.p.) and assessed potential effects on microgliogenesis, inflammation and neurogenesis in the developing hippocampus. LPS administration led to an acute but transient increase in absolute number and density of ionized calciumbinding adaptor molecule 1-immunoreactive microglia, a change attributable to increased proliferation of central nervous system-resident microglia/microglial precursor cells but not infiltration of peripheral monocyte-derived macrophages. qRT-PCR analysis of hippocampal gene expression
\end{abstract}

showed these LPS-mediated changes to be associated with persistent dysregulation of genes associated with both M1 and $\mathrm{M} 2$ microglial phenotypes, indicating prolonged alteration in hippocampal inflammatory status. Further, analysis of progenitor cell regulation in the hippocampal subgranular zone revealed a transient inhibition of the neuronal differentiation pathway up to 2 weeks after LPS administration, a change occurring specifically through effects on type 3 neural progenitor cells and independently of altered cell proliferation or survival of newly born cells. Together, our results show that systemic inflammation occurring during the early neonatal period is sufficient to alter inflammatory status and dysregulate the ongoing process of neurogenesis in the developing hippocampal germinal niche.

(c) 2014 S. Karger AG, Basel

\section{Introduction}

The neuronal population of the adult central nervous system (CNS) is almost exclusively developmentally generated; as such, subtle alterations to the perinatal immune environment may alter the normal course of development, potentially increasing susceptibility to secondary

\begin{tabular}{ll}
\hline KARGER & $\begin{array}{l}\text { Co 2014 S. Karger AG, Basel } \\
0378-5866 / 14 / 0362-0119 \$ 39.50 / 0 \quad \text { Karger }\end{array}$ \\
$\begin{array}{l}\text { E-Mail karger@karger.com } \\
\text { www.karger.com/dne }\end{array}$ & $\begin{array}{l}\text { This is an Open Access article licensed under the terms of the } \\
\text { Creative Commons Attribution-NonCommercial 3.0 Un- } \\
\text { ported license (CC BY-NC) (www.karger.com/OA-license), } \\
\text { applicable to the online version of the article only. Distribu- } \\
\text { tion permitted for non-commercial purposes only. }\end{array}$
\end{tabular}

Peter L.P. Smith

Institute of Neuroscience and Physiology

Sahlgrenska Academy, Box 432

SE-405 30 Gothenburg (Sweden)

E-Mail pete.smith@neuro.gu.se 
CNS insult and predisposing to adult neuropsychiatric disorders such as schizophrenia and autism [1-4]. During early neonatal life, neurogenic potential is progressively restricted to the subventricular zone of the lateral ventricles and the subgranular zone (SGZ) of the hippocampal dentate gyrus, where its persistence throughout adulthood [5-7] is hypothesized to support the important role of the hippocampus in learning and memory.

Under physiological conditions, microglia have numerous functions including synaptic maintenance [8] and phagocytosis of apoptotic newborn cells in the adult hippocampal stem cell niche [9]. In response to pathological alterations to the CNS microenvironment, microglia rapidly assume an 'upregulated' or 'activated' phenotype; undergoing changes in morphology and surface antigen expression, and synthesizing numerous pro- and anti-inflammatory cytokines [10-13]. At the broadest level this upregulated phenotype can be classified as either proinflammatory (M1) or anti-inflammatory (M2) [14], a categorization dependent on the nature of each cell's overall inflammatory profile, which is influenced by the nature and duration of the inflammatory stimulus $[15,16]$. Microglia display both neuroprotective and neuroregenerative potential $[15,17]$ and additionally harbour microbicidal activity, the latter being facilitated by the production and release of reactive oxygen species [18].

Experimentally, systemic inflammation as induced by intraperitoneal administration of the Gram-negative bacterium-derived lipopolysaccharide (LPS) [19-24] or subcutaneous administration of Escherichia coli [25-27] has been shown to upregulate proinflammatory cytokine production and increase microglial activation in the rodent CNS. Furthermore, neonatal induction of central inflammation by subcutaneous $E$. coli administration reduces adult performance in hippocampus-dependent memory tasks, but only if a second peripheral LPS immune challenge is given in close temporal proximity to the test-learning phase [25], an effect attributed to reduced hippocampal neurogenesis [27]. Similarly, neonatal administration of $E$. coli reduces both the survival and neurogenic potential of hippocampal progenitors born within $24 \mathrm{~h}$ of $E$. coli injection [27]. While such research has clearly demonstrated acute consequences of neonatal inflammation on hippocampal progenitors, the subacute and longer-term consequences remain to be investigated.

In this study we stimulated central inflammation in mice through peripheral (intraperitoneal) administration of LPS at postnatal day (P)5, an age when murine developmental neurogenesis is highly active in the hilar germi- nal zone [28], and yolk sac-derived microglial precursors are highly proliferative [29]. We hypothesized that peripheral inflammation occurring during this period would instigate a central inflammatory response, altering microgliogenesis and having a negative impact on the neurogenic potential of SGZ-resident neural progenitor cells (NPCs). Specifically, we investigated the acute, subacute and chronic effects of neonatal LPS-induced systemic inflammation on microgliogenesis, inflammation and various aspects of neurogenesis in the developing murine hippocampus.

\section{Methods}

\section{Animals}

C57Bl/6j mice were sourced from Charles River Laboratories (Germany), and Lys-EGFP-ki mice were obtained from Dr. Tomas Graf, Autonomous University of Barcelona (Spain). Animals were bred at the University of Gothenburg's Laboratory for Experimental Biomedicine and housed with ad libitum access to food and water on a 12-hour light-dark cycle (illuminated 19:00-07:00) at constant temperature $\left(24^{\circ} \mathrm{C}\right)$ and relative humidity (50-60\%). All experimental procedures were approved by the University of Gothenburg's animal ethics committee (No. 344/09, 280/12).

\section{Experimental Manipulations}

Male mice received intraperitoneal injections of LPS at a dose of $1 \mathrm{mg} / \mathrm{kg}$ (Serotype O55:B5; Sigma-Aldrich) or equivalent volumes of saline at P5. We selected this dose on the basis of previous studies demonstrating effects of this dose and administration route on rodent neurogenesis $[21,23,24]$.

\section{BrdU Administration and Tissue Collection}

Mice were randomly allocated to 1 of 4 groups and tissue was collected at the following time points: P7 (acute); P21 and P28 (subacute); and P74 (chronic). Animals composing the acute group received single injections of BrdU (5-bromo-2' -deoxyuridine; $50 \mathrm{mg}$ / kg i.p.) at P6 and were sacrificed $24 \mathrm{~h}$ later (P7); the subacute group received single injections of $\mathrm{BrdU}(50 \mathrm{mg} / \mathrm{kg}$ i.p.) at $\mathrm{P} 19$ and were sacrificed $48 \mathrm{~h}$ later (P21). Neuronal fate specification was investigated in animals injected with $\mathrm{BrdU}(50 \mathrm{mg} / \mathrm{kg}$ i.p. $)$ at $\mathrm{P} 21$ and sacrificed 7 days later (P28). Long-term survival was assessed in a further group receiving BrdU injections (50 mg/ $\mathrm{kg}$ i.p.) once daily from P22 to P25 and sacrificed 49 days later (P74).

\section{Immunohistochemistry}

Mice were deeply anaesthetized and transcardially perfused with ice-cold $0.9 \%$ saline followed by $4 \%$ paraformaldehyde. Brains were rapidly removed, postfixed in $4 \%$ paraformaldehyde for $24 \mathrm{~h}$ at $4^{\circ} \mathrm{C}$, and cryoprotected in $30 \%$ sucrose for a minimum of 3 days. Cryoprotected brains were snap frozen on liquid nitrogen and sectioned serially at 40 or $25 \mu \mathrm{m}$ (for P7 or older animals, respectively) on a Leica CM3050 S cryostat (Leica, Sweden). Cut sections were transferred to cryoprotectant solution (25\% ethylene glycol, $25 \%$ glycerine, in $0.1 \mathrm{M}$ phosphate buffer) and stored at $-20^{\circ} \mathrm{C}$. Stereological estimations of absolute cell number and cell density 
were made on tissue stained for BrdU, phosphohistone-H3 ( $\mathrm{PhH} 3)$, ionized calcium-binding adaptor molecule 1 (Iba1) and doublecortin (DCX). Antigen retrieval steps were included when staining for Iba1, BrdU and DCX; sodium citrate antigen retrieval (10 mM sodium citrate; $\mathrm{pH} 6 ; 97^{\circ} \mathrm{C} ; 10 \mathrm{~min}$ ) was performed prior to Ibal and DCX staining, and hydrochloric acid (HCL) pretreatment $\left(2 \mathrm{M} \mathrm{HCL} ; 37^{\circ} \mathrm{C} ; 30 \mathrm{~min}\right)$ followed by a single wash in borate buffer ( $0.1 \mathrm{M}$; $\mathrm{pH}$ 7.5; room temperature; $10 \mathrm{~min})$ was performed in advance of BrdU staining. With exception pretreatment, all steps proceeded as follows: endogenous peroxidase activity was blocked by a 30 -min incubation with TBS containing $0.6 \%$ hydrogen peroxide, and blocking of non-specific binding sites and tissue permeabilization were achieved by 30 -min incubation in TBS containing $3 \%$ donkey serum and $0.1 \%$ Triton X-100 (hereafter referred to as blocking buffer). Sections were then incubated at $4{ }^{\circ} \mathrm{C}$ overnight with either rat monoclonal anti-BrdU (1:1,000; Accurate Chemical, Westbury, N.Y., USA), goat polyclonal anti-Iba1 (1:500; Abcam, Cambridge, UK), rabbit polyclonal anti-PhH3 (1:1,000; Millipore, Billerica, Mass., USA) or goat anti-DCX (1:200; Santa Cruz, Heidelberg, Germany) diluted in blocking buffer. The sections were subsequently incubated at room temperature for $2 \mathrm{~h}$ with appropriate biotinylated (BT) secondary antibodies diluted in blocking buffer: donkey anti-rat BT (1:1,000; Jackson, Newmarket, UK), donkey anti-goat BT (1:1,000; Jackson) and donkey anti-rabbit BT (1:1,000; Jackson), followed by application of the Vectastain standard ABC kit (Vector, Burlingame, Calif., USA). Visualization was performed with DAB (3,3'-diaminobenzidine; $0.25 \mathrm{mg} / \mathrm{ml}$; Saveen \& Werner, Sweden), $10 \mu \mathrm{l}$ per $1 \mathrm{ml}$ TBS containing $0.3 \mu \mathrm{l}$ hydrogen peroxide $(30 \%)$ and $5 \mu \mathrm{l}$ of $8 \% \mathrm{NiCl}_{2}$ (Sigma-Aldrich, Sweden).

Phenotyping of BrdU-labelled cells was performed via double immunofluorescence staining combining either rat monoclonal anti-BrdU with antibodies to Iba1 (microglial proliferation), DCX (neuronal commitment) and NeuN (neuronal survival), or by quadruple staining combining rat monoclonal anti-BrdU with antibodies to nestin, glial fibrillary acidic protein (GFAP) and DCX (precursor development). Sodium citrate and HCL pretreatment was performed prior to immunofluorescence staining; importantly, it was necessary to conduct the sodium citrate step in advance of HCL pretreatment to preserve BrdU antigenicity. Blocking buffer was then applied for $30 \mathrm{~min}$, and the sections were incubated at $4^{\circ} \mathrm{C}$ overnight with relevant combinations of the following primary antibodies diluted in blocking buffer: rat monoclonal anti-BrdU, goat anti-Iba1, goat anti-DCX (all as described above), mouse monoclonal anti-NeuN (1:250; Millipore), mouse antinestin (1:100; Abcam) and chicken anti-GFAP (1:1,000; Covance, Princeton, N.J., USA). Secondary antibodies were diluted to 1:1,000 in blocking buffer and applied for $2 \mathrm{~h}$ at room temperature: donkey anti-rat Cy3 (Jackson), donkey anti-mouse Alexa 488 (Molecular Probes/Invitrogen, Carlsbad, Calif., USA), donkey antigoat Alexa 488 (Molecular Probes/Invitrogen), donkey anti-mouse CF647 (VWR, Lutterworth, UK), donkey anti-goat CF555 (VWR), donkey anti-chicken CF488 (Sigma-Aldrich, Sweden) and donkey anti-rat DyLight 405 (Jackson).

Staining for goat anti-Iba1 and goat anti-CD31 (1:200; R\&D Systems, Abingdon, UK) on tissue derived from Lys-EGFP-ki mice was performed in the absence of Triton X-100 to limit quenching of EGFP fluorescence.

Effects of Systemic Inflammation on the

Developing Hippocampus

\section{Microscopy and Quantification Strategies}

Stereological estimations of absolute cell number and cell density were performed on serially spaced sections representing the entire hippocampal formation, using a Leica DM600 B microscope (Leica, Heidelberg, Germany) equipped with Stereo Investigator (MBF Biosciences, Williston, Vt., USA). BrdU-, DCX- and PhH3-positive cells were counted exhaustively, absolute cell numbers were derived via multiplication of total counted cells by number of series per brain (the latter value varying depending on the time point and section thickness). At P7, the absolute number of BrdUpos cells was quantified in the hippocampal granule cell layer (GCL) and SGZ as at this stage of development, proliferative potential is not limited to the SGZ. At $\mathrm{P} 21$ and P74, BrdU- and $\mathrm{PhH} 3$-immunoreactive cells, respectively, were quantified in the SGZ as proliferation was limited to this region. In the P21-P28 and P21-P74 differentiation studies, cells were quantified in the SGZ and GCL as newly born BrdUlabelled cells migrate into the GCL during maturation. Absolute number and density of Iba ${ }^{\text {pos }}$ cells were assessed using the optical fractionator. Representative images of DAB-stained sections were captured on a Zeiss Axio Imager Z2 equipped with Zeiss AxioVision image capture software (Zeiss, Oberkochen, Germany). The percentage of newly born microglia at P7 was assessed by investigation of BrdU immunoreactivity in a minimum of 100 Iba $1^{\text {pos }}$ cells randomly sampled from reconstructed tile-scanned z-stacks of entire hippocampi captured on a Zeiss Axio Observer upright microscope equipped with an ApoTome module and Zen Blue software (Zeiss); resultant $\mathrm{z}$-stacks were imported to Stereo Investigator for analysis. Neuronal precursor phenotyping studies involved analysis of immunohistochemical marker coexpression in a minimum of $100 \mathrm{BrdU}^{\text {pos }}$ cells; percentage coexpression values were then combined with stereologically derived estimates of the absolute BrdU ${ }^{\text {pos }}$ cell number to provide an estimate of the absolute number of double-labelled cells. BrdU/DCX expression was investigated using a Leica TCS SP2 confocal microscope (Leica, Heidelberg), and effects on particular hippocampal NPC populations were assessed in BrdU/nestin/GFAP/DCX-costained tissue (progenitor populations characterized as follows: type 1, BrdU/nestin/GFAP; type 2a, BrdU/ nestin; type 2b, BrdU/nestin/DCX; type 3, BrdU/DCX [30]); here, coexpression was investigated using a Zeiss LSM 700 inverted confocal microscope. Z-projections and orthogonal reconstructions were produced in ImageJ (NIH, Bethesda, Md., USA; http://rsbweb.nih.gov/ij/).

\section{Tissue Collection for RNA Isolation}

Mice were deeply anaesthetized and transcardially perfused with ice-cold $0.9 \%$ saline, and brains rapidly removed and microdissected. Whole hippocampi were either snap frozen on liquid nitrogen and subsequently stored at $-80^{\circ} \mathrm{C}$ or transferred to icecold Hanks' buffered salt solution (Life Technologies, Stockholm, Sweden) prior to magnetic antibody-based cell sorting (MACS).

\section{Isolation of Hippocampal Microglia}

CD11b ${ }^{\text {pos }}$ microglia were isolated from hippocampi microdissected from P21 mice. Briefly, isolated hippocampi were dissociated into single cell suspensions using a gentleMACS Dissociator and papain-based Neural Tissue Dissociation kit (Miltenyi Biotec Norden AB, Lund, Sweden), myelin debris was removed from the single-cell suspensions with Myelin Removal 
Table 1. Primers used for qRT-PCR

\begin{tabular}{lllll}
\hline Gene & Official symbol & NCBI ID & Primer & Product number \\
\hline Gapdh & Gapdh & NM_008084 & Mm_Gapdh_3_SG & QT01658692 \\
Hprt & Hprt & NM_013556 & Mm_Hprt_1_SG & QT00166768 \\
Cd86 & Cd86 & NM_019388 & Mm_Cd86_1_SG & QT01055250 \\
Il1b & Il1b & NM_008361 & Mm_Il1b_2_SG & QT01048355 \\
iNos & LOC673161 & XM_001004823 & Mm_LOC673161_1_SG & QT01547980 \\
Il6 & Il6 & NM_031168 & Mm_IL6_1_SG & QT00098875 \\
YM1 & Chi3L3 & NM_009892 & Mm_Chi313_2_SG & QT02241722 \\
CD206 & Mrc1 & NM_008625 & Mm_Mrc1_1_SG & QT00103012 \\
Arg1 & Arg1 & NM_007482 & Mm_Arg1_1_SG & QT00134288 \\
Il10 & Il10 & NM_010548 & Mm_IL10_1_SG & QT00106169 \\
\hline
\end{tabular}

Beads II (Miltenyi Biotec) and microglia were isolated with antiCD11b microbeads (Miltenyi Biotec). Separations were performed with an autoMACS Pro Separator (Miltenyi Biotec). All procedures were conducted in accordance with the manufacturer's guidelines. Isolated microglia were subject to direct RNA processing.

\section{$R N A$ Extractions and $q R T-P C R$}

Total RNA was isolated from the left hippocampus using a Qiagen RNeasy Lipid Tissue Mini Kit (Qiagen, Sollentuna, Sweden) or from MACS-isolated microglia using a Qiagen RNeasy Micro Kit (Qiagen) in accordance with the manufacturer's instructions. RNA concentrations were assessed using a NanoDrop 1000 Spectrophotometer (NanoDrop, Wilmington, Del., USA). Reverse transcription was performed in duplicate for each sample with a QuantiTect Reverse Transcription Kit (Qiagen); in the case of MACS-isolated microglia, duplicates were later pooled due to low RNA yield. qRT-PCR was performed using a QuantiFast SYBR Green PCR Kit (Qiagen) following a 2-step cycling protocol ( 5 min of initial denaturation followed by $10 \mathrm{~s}$ of denaturation at $95^{\circ} \mathrm{C}$ and $30 \mathrm{~s}$ of annealing/extension at $60^{\circ} \mathrm{C}$ for 25 cycles) on a Roche LightCycler 480 (Roche, Bromma, Sweden). Amplification specificity was confirmed by melting curve analysis. All primers were purchased from Qiagen (table 1). Quantification was conducted in accordance with the standard curve method, and expression values were normalized to the geometric mean of the reference genes glyceraldehyde 3-phosphate dehydrogenase $(G A P D H)$ and hypoxanthine phosphoribosyltransferase 1 (Hrpt1).

\section{Statistics}

Stereological data are presented as group means \pm SEM and qRT-PCR data are presented as mean percent changes (relative to control) \pm SEM. Comparisons were performed by Student's $t$ test and differences were considered significant at $* \mathrm{p} \leq 0.05$, ${ }^{* *} \mathrm{p} \leq 0.01$ and ${ }^{* * *} \mathrm{p} \leq 0.001$. Analyses were performed using SPSS (PASW Statistics, release 17.02).

\section{Results}

Perinatal LPS Administration Acutely Increases Microglial Density in the Developing Hippocampus through Increased Proliferation, Not Infiltration

We first sought to assess the effect of peripheral immune stimulation on the microglial population of the developing hippocampus. LPS was administered intraperitoneally at a dose of $1 \mathrm{mg} / \mathrm{kg}$ to $\mathrm{P} 5$ pups and tissue harvested at P7, P21 and P74. Stereological estimation revealed a transient $342.1 \%$ increase in absolute number ( $\mathrm{p}<0.05$; fig. $1 \mathrm{a})$ and $214.4 \%$ increase in density $(\mathrm{p}<0.05$; fig. 1b) of Iba ${ }^{\text {pos }}$ microglia $48 \mathrm{~h}$ after LPS administration; this change was coupled with a shift towards a more active but not phagocytic morphology, with cells displaying characteristically thickened processes (fig. 1c, d, 2d, e). With developmental progression and concomitant increase in microglial cell number, differences in absolute cell number and density were rapidly lost (fig. 1a, b; P21, P74). Interestingly, LPS administration appeared to prematurely boost microglial cell density to a level similar to that observed in more mature animals (fig. 1b).

We next examined whether the additional Iba $1^{\text {pos }}$ cells observed $48 \mathrm{~h}$ after LPS administration were derived from increased proliferation of primitive microglial progenitors/microglia or infiltration of peripheral monocytes. To assess proliferation, BrdU was administered $(50 \mathrm{mg} / \mathrm{kg}$ i.p.) at P6 (24 h after LPS administration) and tissue was harvested $24 \mathrm{~h}$ later (P7); infiltration was assessed in LysEGFP- $k i$ mice, which express EGFP only in mature peripheral granulomyelomonocytic cells and not in microglia [31, 32], $48 \mathrm{~h}$ after LPS administration (P7). Our findings show a $53.1 \%$ increase $(\mathrm{p}<0.05$; fig. $2 \mathrm{a}-\mathrm{e})$ in the percentage of newly proliferated $\mathrm{Iba} 1^{\text {pos }} / \mathrm{BrdU}^{\mathrm{pos}}$ cells in 
Fig. 1. Systemic administration of LPS (1 mg/kg i.p.) at P5 acutely increases the absolute number and density of microglial cells in the hippocampal formation. Stereological assessment reveals a significantly increased absolute number (a) and density (b) of Iba1-immunoreactive cells at P7 (saline: $\mathrm{n}=8$; LPS: $\mathrm{n}=6$ ) but not at P21 or P74 following LPS administration $(\mathrm{n}=8$ per group). a, b Values are presented as means \pm SEM. Student's $t$ test between groups at each time point. ${ }^{*} \mathrm{p} \leq 0.05$. c, $\mathbf{d}$ Representative images showing hippocampal Ibal immunoreactivity $48 \mathrm{~h}$ after saline (c) or LPS (d) administration. Scale bar $=200 \mu \mathrm{m}$.
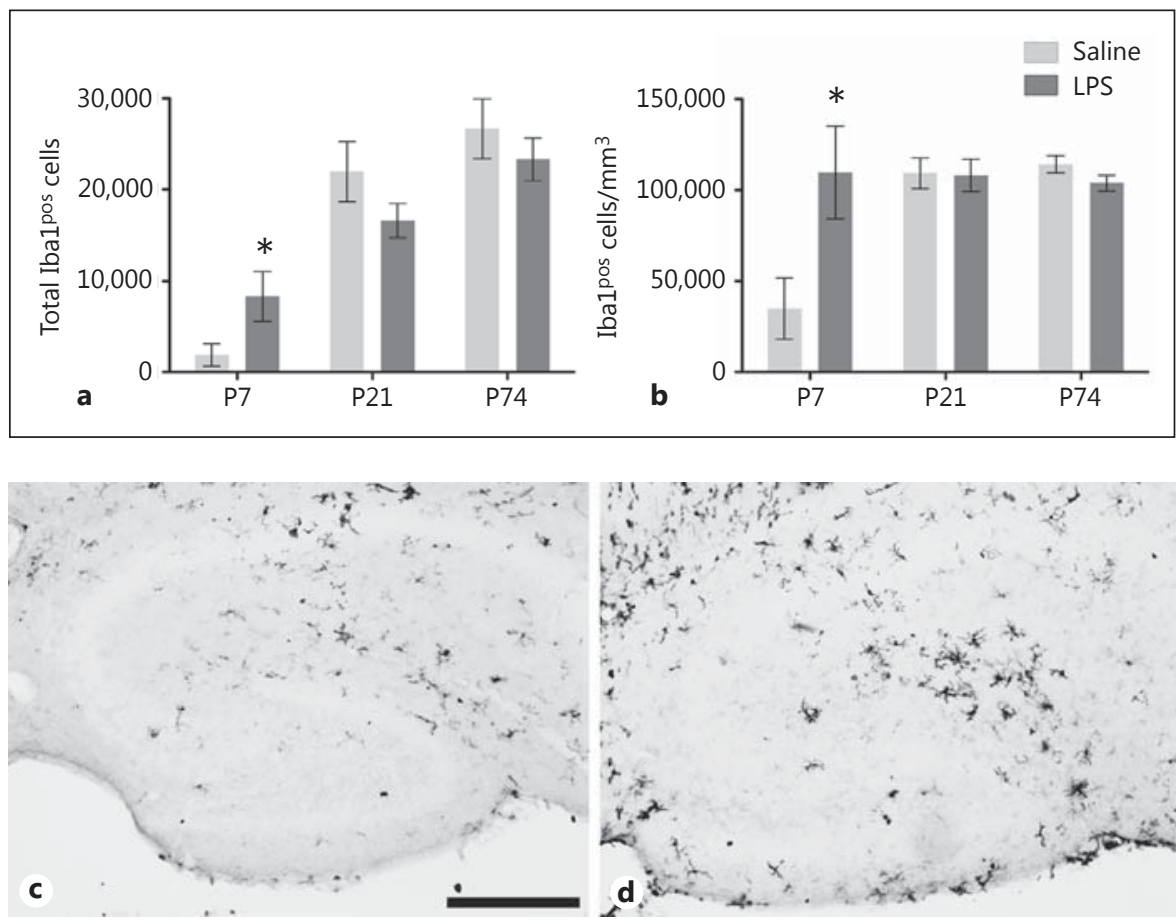

the hippocampus $48 \mathrm{~h}$ after LPS administration. Whilst a small number of $L y s$-EGFP ${ }^{\text {pos }}$ cells could be observed in the hippocampus following saline or LPS administration (fig. 2f, g), these cells did not coexpress Ibal (Lys$\mathrm{EGFP}^{\mathrm{pos}} / \mathrm{Iba1}{ }^{\text {neg; }}$; fig. $2 \mathrm{~h}, \mathrm{i}$ ) and were localized within the lumen of $\mathrm{CD} 31^{\text {pos }}$ cerebral blood vessels (fig. $2 \mathrm{j}$ ) most likely representing residual blood-borne granulocytes not cleared during perfusion $[31,33]$. We hence conclude that peripheral monocytes do not contribute to the CNS microglia population following systemic LPS stimulation in this model. Together these data strongly indicate that peripheral administration of LPS during the early neonatal period increases the proliferation of primitive microglial progenitor cells, transiently increasing absolute population size and leading to premature attainment of adult microglial density in the developing hippocampus.

\section{Peripheral LPS Alters Hippocampal Expression of}

Genes Associated with Microglial Phenotype

With the observation of increased acute-phase microglial proliferation transiently increasing the hippocampal microglial population size, we hypothesized that a proportion of the stable microglial population in LPSadministered animals may have been born during the acute inflammatory period and, hence, might display altered inflammatory phenotypes. We employed qRT-PCR

Effects of Systemic Inflammation on the Developing Hippocampus to assess mRNA expression of genes associated with M1 (Cd68, Il1b, iNOS and Il6) and M2 (Ym1, Cd206, Arg1 and Il10) microglial phenotypes in the developing hippocampus. Our results indicate a mixed M1/M2 response following LPS administration with increased expression of both the M1 gene $C d 86(+133.9 \%$; $\mathrm{p}<0.001)$ and the M2 gene $Y m 1(+85.0 \%$; $\mathrm{p}<0.05)$ at $\mathrm{P} 7$ (fig. $3 \mathrm{a})$, and regulation of the M1 genes $i N O S(+53.6 \%$; $<<0.01)$ and Il6 $(-70.0 \%$; $\mathrm{p}<0.05)$ at P21 (fig. 3b).

As astrocytes may also produce and elaborate the cytokines Il6 and iNOS [34, 35], we further analysed gene expression levels in MACS-isolated hippocampal microglia from P21 animals (fig. 3c). Here we observed a strong but statistically insignificant upregulation of $I l 6$ (158.8\%; $\mathrm{p}=0.16)$ and $i N O S(121.8 \% ; \mathrm{p}=0.22)$ occurring in response to LPS administration.

\section{Hippocampal Progenitor Proliferation Is Unaltered by Perinatal LPS Treatment}

As LPS administration acutely increased microglial density and altered expression of several inflammationassociated genes in the developing hippocampus, we further examined the potential effects of LPS on hippocampal cell proliferation. At acute (P8) and subacute (P21) time points, BrdU was administered $24 \mathrm{~h}(\mathrm{P} 8)$ and $48 \mathrm{~h}$ (P21) prior to sacrifice, and proliferation was determined 

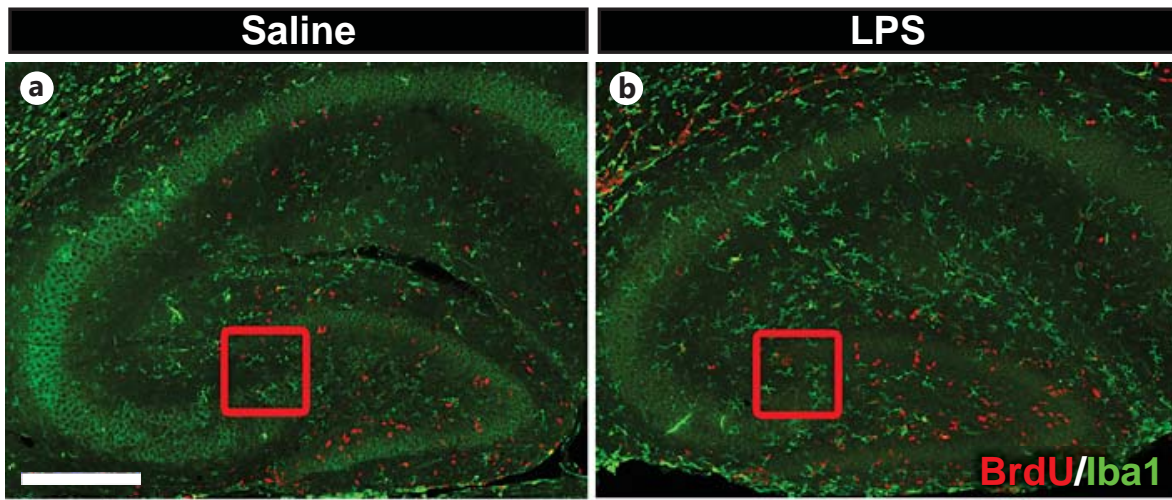

Fig. 2. Increased microglial cell density at P7 is caused by microglial proliferation and not infiltration of peripheral monocytes/ macrophages. Animals received LPS ( $1 \mathrm{mg} / \mathrm{kg}$ i.p.) at P5 followed by $50 \mathrm{mg} / \mathrm{kg}$ BrdU at P6. Tissue was harvested at P7. ae P5 LPS administration significantly increased the percentage of Ibal ${ }^{\text {pos }} / \mathrm{BrdU}^{\mathrm{pos}}$, newly born microglia in the P7 hippocampus (saline: $n=6$; LPS: $n=5$; c). Representative photomicrographs of the hippocampus in saline- (a) and LPS-treated (b) animals. c Values are presented as means \pm SEM. Student's t test between groups at each time point. ${ }^{*} \mathrm{p} \leq 0.05$. d, e Enlargements of insets in $\mathbf{a}$ and $\mathbf{b}$, respectively. e Arrows: BrdU/Ibal coimmunoreactivity. f-i Few EGFP-positive peripheral myeloidderived cells can be detected in the hippocampus of Lys-EGFP-ki mice following either saline $(\mathbf{f}, \mathbf{h})$ or LPS $(\mathbf{g}, \mathbf{i})$ administration. $\mathbf{h}$, i Enlargements of insets in $\mathbf{f}$ and $\mathbf{g}$, respectively, showing that detectable EGFP is never present in Iba1 ${ }^{\text {pos }}$ microglia. j Immunostaining for CD31 confirms the intraluminal localization of EGFPpos cells. Scale bars $=200 \mu \mathrm{m}(\mathbf{a}, \mathbf{f}), 20 \mu \mathrm{m}(\mathbf{d}, \mathbf{h}, \mathbf{i})$ and $5 \mu \mathrm{m}(\mathbf{j})$.
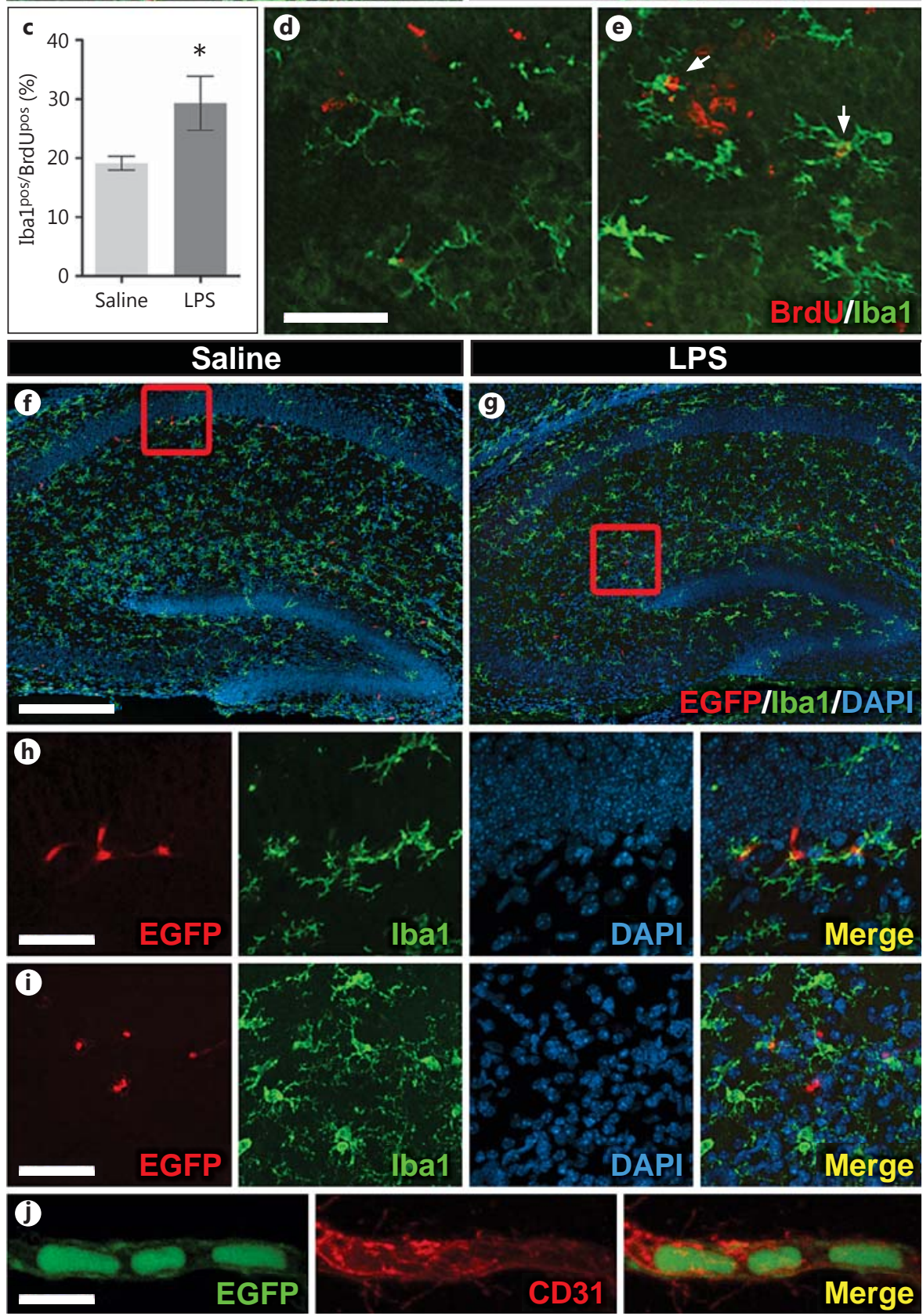


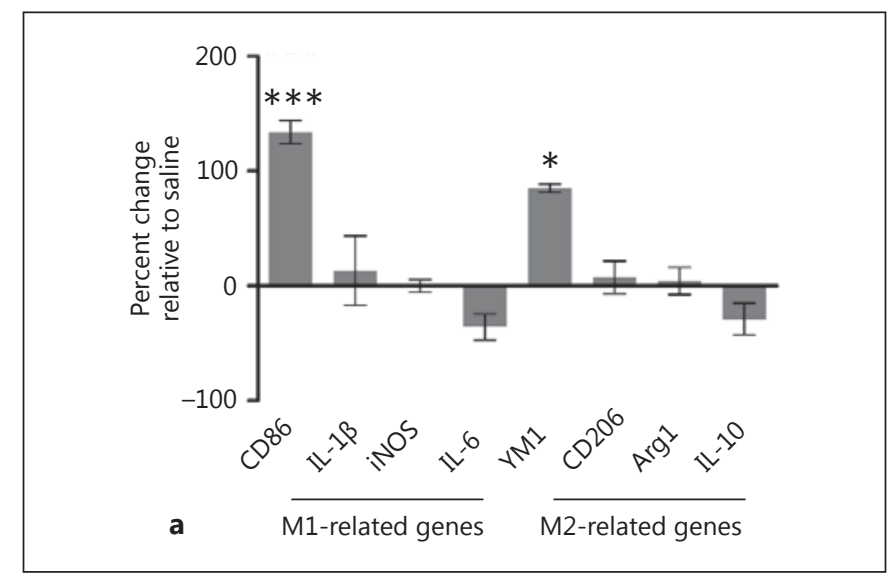

Fig. 3. Peripheral LPS administration alters hippocampal expression of genes associated with pro- (M1) and anti-inflammatory (M2) microglial phenotypes. Animals received LPS (1 mg/kg i.p.) at P5 and were sacrificed at P7 and P21; gene expression, as assessed by qRT-PCR, is presented as percent change (relative to saline-injected control animals). Values are presented as means \pm SEM. Student's t test between groups at each time point. ${ }^{*} \mathrm{p} \leq 0.05$, ${ }^{* *} \mathrm{p} \leq 0.01,{ }^{* * *} \mathrm{p} \leq 0.001$. $\mathbf{a}, \mathbf{b}$ Regulation of gene expression in whole microdissected hippocampi at $48 \mathrm{~h}(\mathrm{n}=6$ per group) and 14 days ( $\mathrm{n}=12$ per group), respectively, after LPS administration. c Regulation of gene expression in MACS-isolated (CD11b ${ }^{\text {pos }}$ ) hippocampal microglia at P21 ( $n=10$ per group).

by stereological quantification of the absolute number of BrdU ${ }^{\text {pos }}$ cells (fig. 4a, b). The endogenous mitotic marker $\mathrm{PhH} 3$ was used to identify proliferating cells at P74 (fig. 4c). Neonatal peripheral immune stimulation had no effect on cell proliferation in the hippocampus at any of the time points examined (fig. $4 \mathrm{a}-\mathrm{c}$ ).

\section{Perinatal LPS Administration Inhibits Neuronal}

Differentiation Two Weeks after Administration

We next addressed LPS effects on the stem and progenitor cell populations of the developing SGZ. Here we chose to perform analyses 2 weeks after peripheral administration of LPS, aiming to build upon previous work by Bland et al. [27] which showed reduced neurogenesis among hippocampal progenitors born within $24 \mathrm{~h}$ of subcutaneous E. coli stimulation in P4 rats.

Focussing on neurogenesis, we first undertook a shortterm differentiation study with BrdU being administered at P21 and cell fate assessed via DCX coimmunoreactivity (type $2 \mathrm{~b}$ and 3 NPCs) 7 days later. Absolute numbers
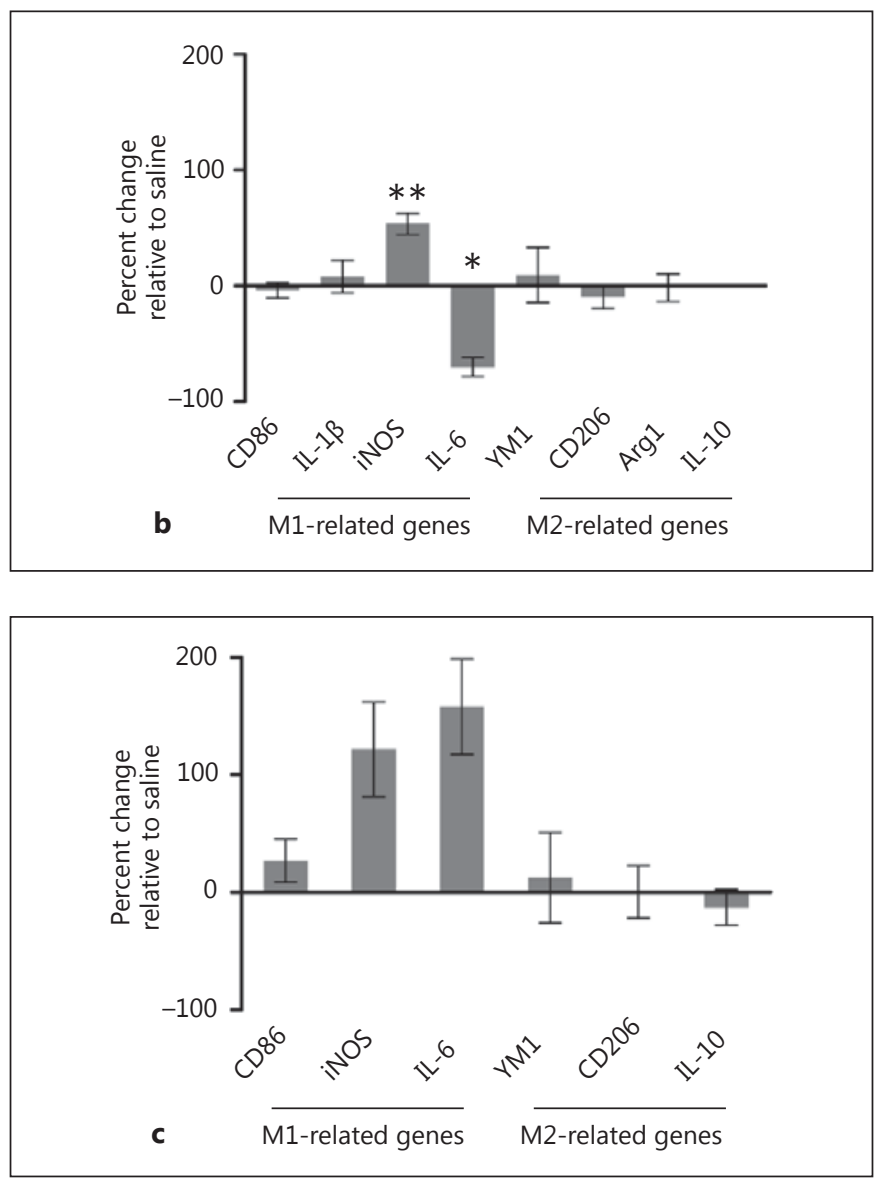

of BrdUpos (all labelled cells; fig. 5a) and BrdUpos/DCX ${ }^{\text {pos }}$ cells (type $2 \mathrm{~b}$ and type 3 progenitors; fig. $5 \mathrm{~b}-\mathrm{d}$ ) in the hippocampal SGZ were stereologically assessed at P28. LPS administration led to a significant $(\mathrm{p}<0.05) 24 \%$ reduction in the number of newly born DCX ${ }^{\text {pos }}$ type $2 \mathrm{~b}$ and type 3 progenitor cells in the P28 hippocampus (fig. 5b). This effect occurred in the absence of altered survival of BrdU ${ }^{\text {pos }}$ cells (fig. 5a; $p>0.05$ ).

As the proliferating stem and progenitor cells of the SGZ can be divided into at least 4 subpopulations based on their expression of the stem cell/astrocyte markers nestin and GFAP, and the transiently expressed early neuronal marker DCX [30], we further investigated which specific subset of SGZ progenitors was susceptible to LPSmediated changes (fig. 6). Here, mice received LPS at P5; proliferating cells were labelled with BrdU at P19 and tissue was analysed at P21. We observed a $35 \%(\mathrm{p}<0.05)$ reduction in type 3 (BrdU ${ }^{\text {pos }} / \mathrm{DCX}^{\mathrm{pos}}$ ) late-stage precursor cells in response to LPS stimulation (saline: 1,764.2 \pm 432.6; LPS: $1,133.1 \pm 570.5$ ) with no detectable effect on 

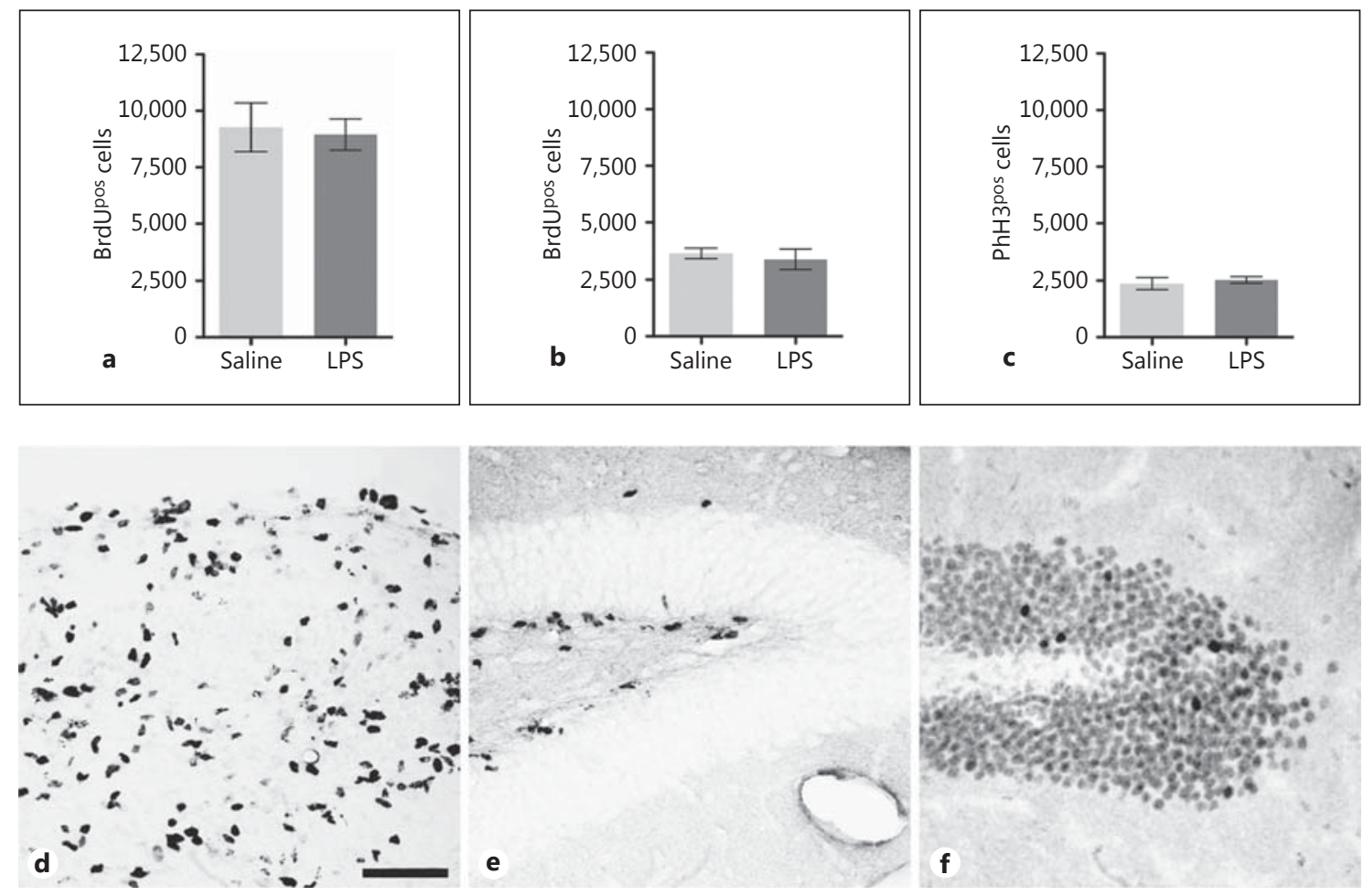

Fig. 4. LPS administration ( $1 \mathrm{mg} / \mathrm{kg}$ i.p.) at P5 has no effect on proliferation of cells present in the hippocampus at acute $(\mathbf{a}, \mathbf{d})$, subacute $(\mathbf{b}, \mathbf{e})$ or chronic time points $(\mathbf{c}, \mathbf{f})$. BrdU $(50 \mathrm{mg} / \mathrm{kg})$ was administered 24 h (P7; saline: $\mathrm{n}=6$; LPS: $\mathrm{n}=5$ ) and $48 \mathrm{~h}$ (P21; saline: $\mathrm{n}=7$; LPS: $\mathrm{n}=8$ ) prior to sacrifice, and immunoreactivity was assessed as an indicator of cell proliferation (a, b, respectively). At P74 (saline: $\mathrm{n}=10$; LPS: $\mathrm{n}=11$ ) proliferation was quantified via immunoreactivity of the mitotic marker $\mathrm{PhH} 3$ (c). Please note: im- munoreactive cells were quantified in the GCL and SGZ at P8 as proliferation is widespread at this age; at P21 and P74, immunoreactive cells were only quantified in the SGZ. The photomicrographs display immunoreactivity for BrdU at P7 (d) and P21 (e), and for PhH3 at P74 (f). Values represent means \pm SEM. Student's $t$ test between groups for cell number at each time point. Scale bar $=50 \mu \mathrm{m}$.
Fig. 5. LPS administration ( $1 \mathrm{mg} / \mathrm{kg}$ i.p. $)$ at P5 significantly impairs neuronal fate specification among SGZ progenitors in the subacute postinflammatory environment. A single BrdU injection ( $50 \mathrm{mg} / \mathrm{kg}$ i.p.) was given at $\mathrm{P} 21$ and neuronal commitment examined 7 days later by assessment of BrdU/ DCX coimmunoreactivity. a LPS administration had no effect on short-term survival of proliferating cells labelled at P21 (saline: $\mathrm{n}=8$; LPS: $\mathrm{n}=8$ ). $\mathbf{b}$ LPS significantly reduced neuronal fate specification among cells born at P21 (saline: $\mathrm{n}=7$; LPS: $\mathrm{n}=8$ ). a, b Values are presented as means \pm SEM. Student's $\mathrm{t}$ test between treatments. ${ }^{*} \mathrm{p} \leq$ 0.05. c Z-projection displaying BrdU/DCX coimmunoreactivity. d Orthogonal reconstructions showing coexpression of BrdU and DCX. Scale bars $=10 \mu \mathrm{m}$ (c) and $5 \mu \mathrm{m}$ (d).
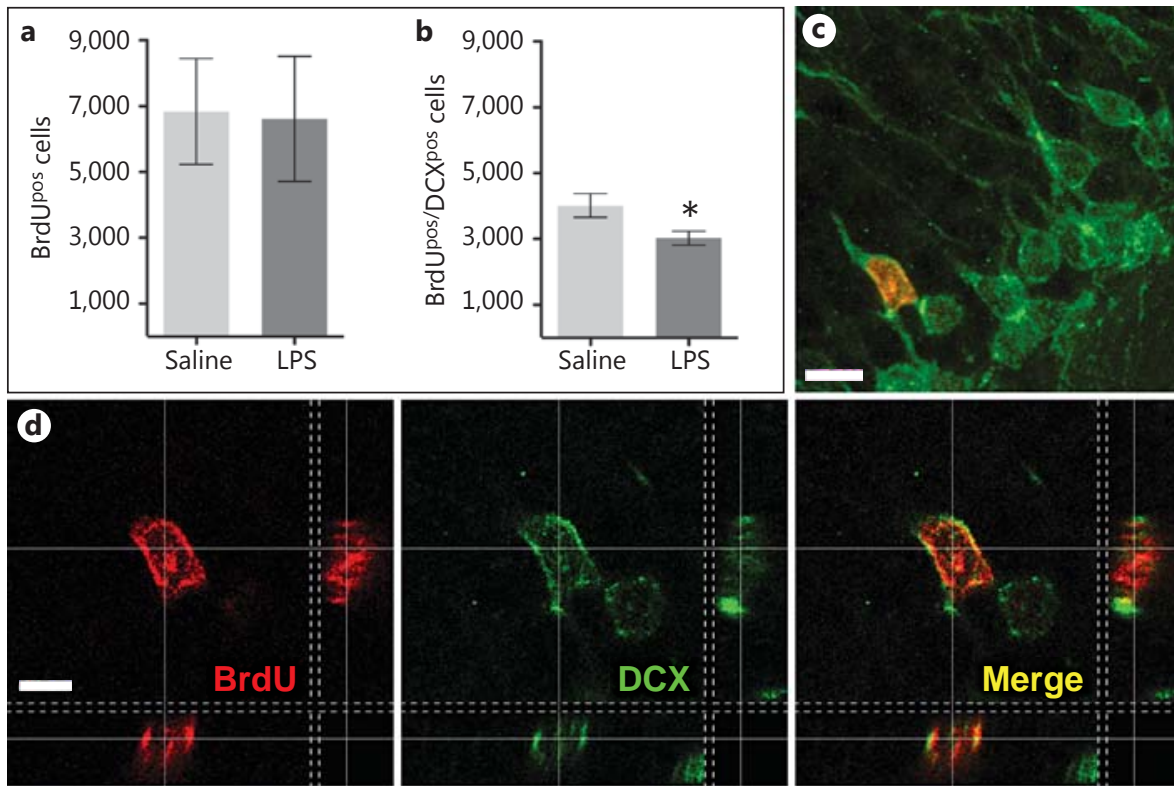
Fig. 6. LPS administration ( $1 \mathrm{mg} / \mathrm{kg}$ i.p.) at $\mathrm{P} 5$ significantly reduced the number of type 3 neuronal precursors in the early postnatal hippocampal SGZ. A single injection of BrdU $(50 \mathrm{mg} / \mathrm{kg})$ was made at P19 and tissue harvested at P21. Immunoreactivity for nestin, GFAP and DCX was used to assess fate specification and maturation of newly proliferated (BrdU ${ }^{\circ o s}$ ) precursor cells. a Response of hippocampal precursor populations to LPS ( $n=8$ per group; precursor classification as follows: type 1 - BrdU/nestin/ GFAP, type $2 \mathrm{a}-\mathrm{BrdU} /$ nestin, type $2 \mathrm{~b}-$ BrdU/nestin/DCX, type 3 - BrdU/DCX). Values are presented as means \pm SEM. Student's t test between treatments. ${ }^{*} \mathrm{p} \leq$ 0.05 . b Representative maximum intensity projection of $\mathrm{BrdU} /$ nestin/DCX/ GFAP immunoreactivity in the P19 hippocampus. c-g Enlargement of inset in $\mathbf{b}$, displayed as individual channels. Arrows: locations of BrdUpos nuclei; bottom-left arrow: $\mathrm{BrdU}^{\text {pos/nestin }}{ }^{\text {pos/GFAPpos }}$ type 1 NPC extending a characteristic radial glia-like process through the molecular layer; remaining arrows: BrdU ${ }^{p o s}$ / nestin ${ }^{\text {pos }} / \mathrm{DCX}^{\text {pos }}$ type $2 \mathrm{~b}$ NPCs. Scale bars $=50 \mu \mathrm{m}(\mathbf{b})$ and $10 \mu \mathrm{m}(\mathbf{c})$.

Fig. 7. LPS ( $1 \mathrm{mg} / \mathrm{kg}$ i.p. at P5) does not affect long-term cell (BrdU $\left.{ }^{p o s} / \mathrm{NeuN}^{\text {neg }}\right)$ or neuronal (BrdU ${ }^{\text {pos }} / \mathrm{NeuN}^{\mathrm{pos}}$ ) survival. a, b Cell (a) and neuronal (b) survival ( $\mathrm{n}=10$ per group) of cells labelled between P22 and P25 (50 mg/kg i.p. once per day) and analysed at P74. Values are presented as means \pm SEM. Student's $t$ test between treatments. c Z-projection displaying $\mathrm{BrdU} / \mathrm{NeuN}$ coimmunoreactivity. d Orthogonal reconstructions showing coexpression of BrdU and NeuN in the GCL/ SGZ. Scale bars $=10 \mu \mathrm{m}(\mathbf{c})$ and $5 \mu \mathrm{m}(\mathbf{d})$.
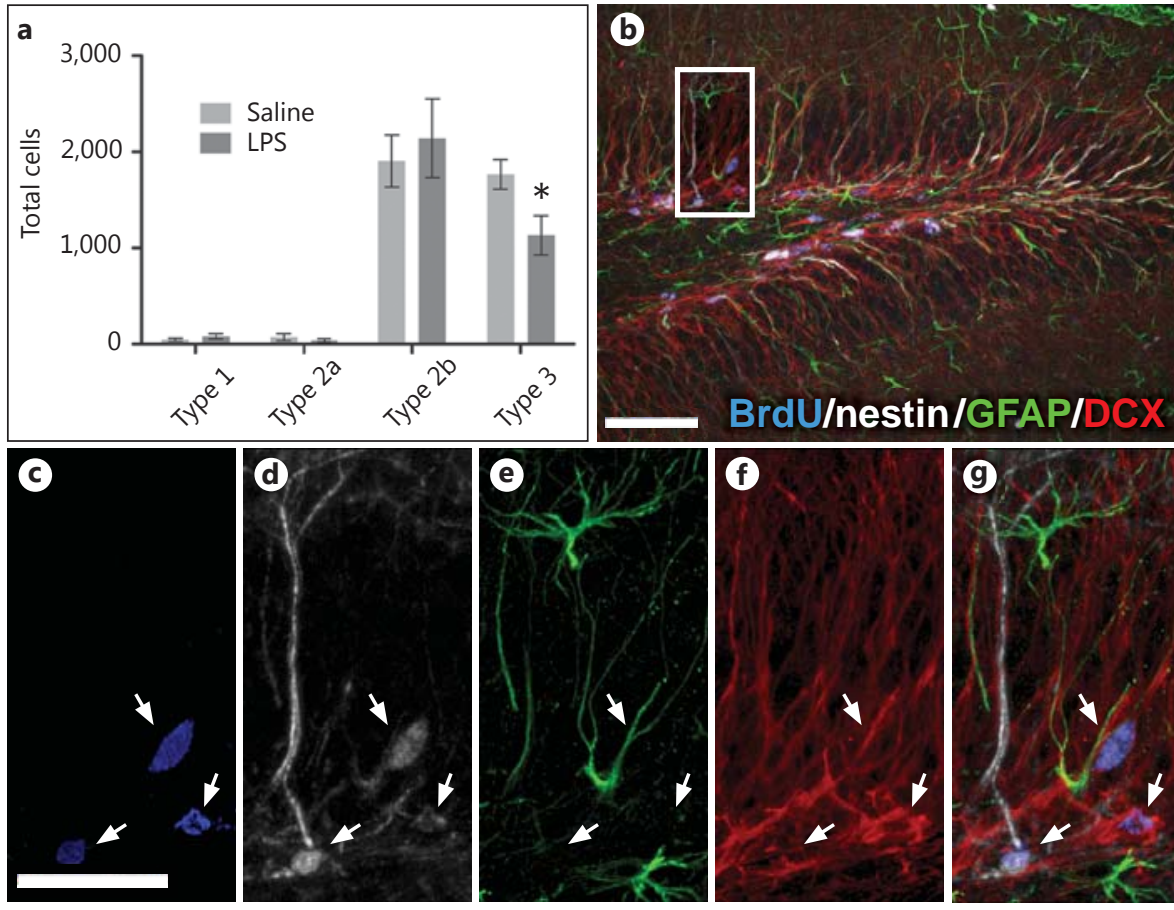
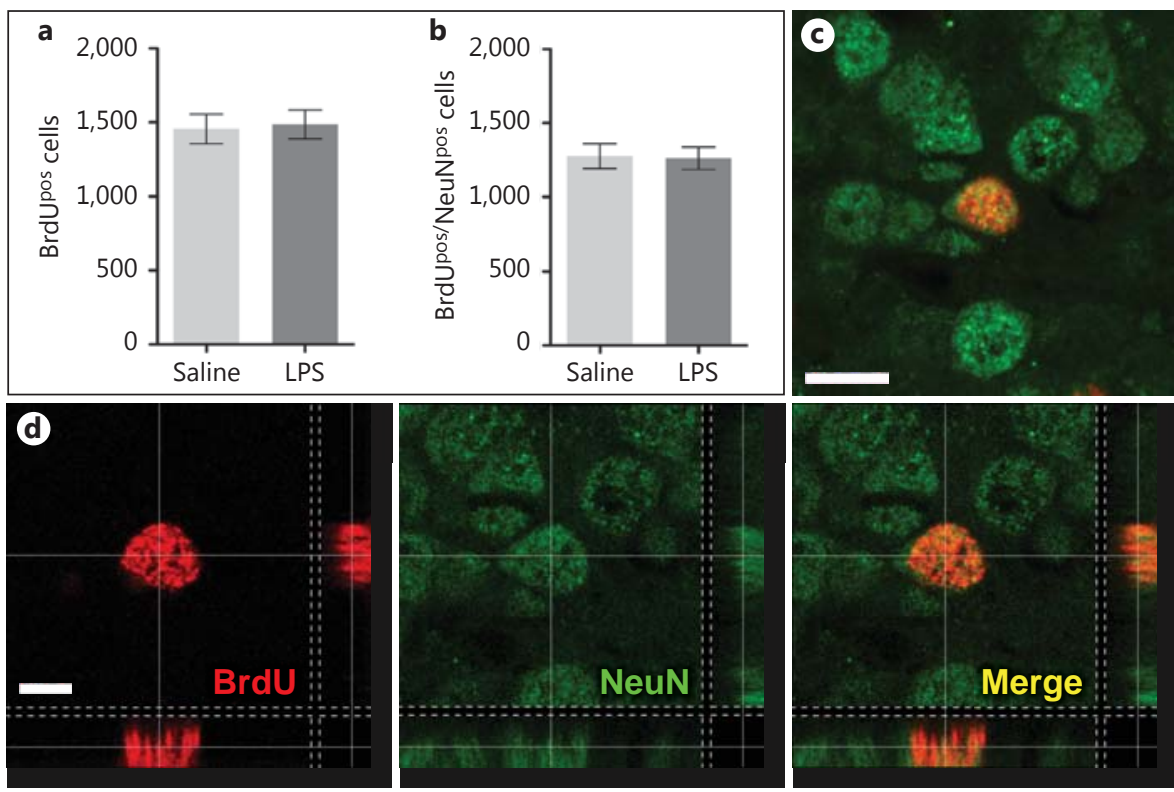

Effects of Systemic Inflammation on the Developing Hippocampus
Dev Neurosci 2014;36:119-131 DOI: $10.1159 / 000359950$ 
Fig. 8. Perinatal LPS ( $1 \mathrm{mg} / \mathrm{kg}$ i.p. at P5) does not alter the number of DCX ${ }^{\text {pos }}$ neuroblasts present in the P74 hippocampus. a Absolute number of DCX ${ }^{\text {pos }}$ cells in the P74 hippocampus ( $\mathrm{n}=10$ per group). Values are presented as means \pm SEM. Student's t test between treatments. b, c Representative photomicrographs of DCX-immunoreactive cells lining the hippocampal SGZ at P74 in saline- (b) and LPS-treated (c) animals. Scale bar $=50 \mu \mathrm{m}$.
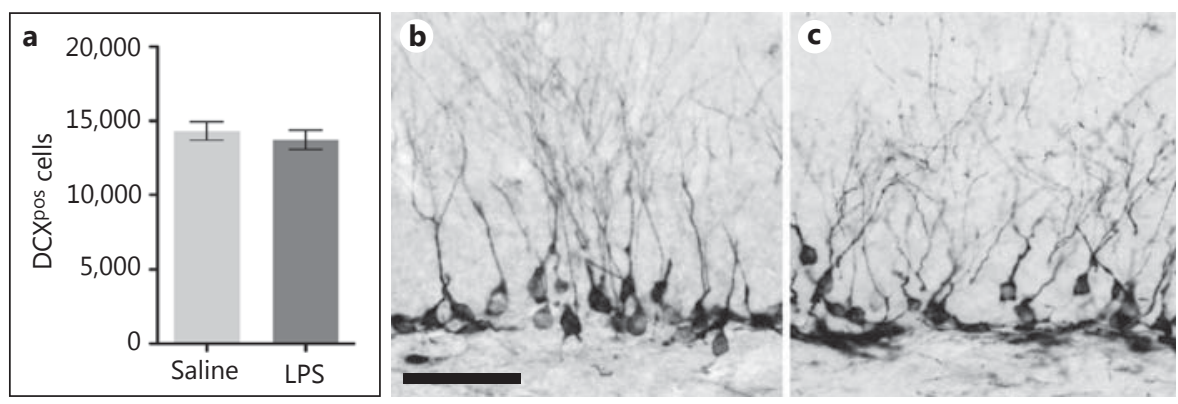

the absolute number of type 1 (BrdU ${ }^{\text {pos }} /$ nestin $^{\text {pos/ }}$ GFAPpos; saline: $50.2 \pm 45.8$; LPS: $84.9 \pm 76.36$ ), type $2 \mathrm{a}$ (BrdUpos/nestin ${ }^{\text {pos; }}$ saline: $75.3 \pm 99.0$; LPS: $42.6 \pm 53.7$ ) or type $2 \mathrm{~b}\left(\mathrm{BrdU}{ }^{\text {pos }} /\right.$ nestin $^{\text {pos }} / \mathrm{DCX}^{\text {pos; }}$; saline: $1,903.3 \pm$ 768.1; LPS: 2,142.4 \pm 1,163.4) cells (fig. 6a).

Together these data indicate an LPS-mediated decrease in absolute number of newly born SGZ progenitors committed to neuronal fate, a change manifest in the reduced size of the type 3 progenitor cell population.

\section{Reduced Neuronal Differentiation between P21 and P28 Coupled to Enhanced Long-Term Neuronal Survival}

Having shown that neonatal peripheral immune stimulation inhibits neuronal fate commitment amongst NPCs entering the S phase of the cell cycle at P21 and P19 (fig. 5b, 6a, respectively), we investigated the long-term survival and fate of cells labelled with BrdU daily between P22 and P25; the absolute number of BrdU ${ }^{\text {pos }}$ (survival; fig. 7a) and BrdU ${ }^{\text {pos }} / \mathrm{NeuN}^{\text {pos }}$ cells (neuronal maturation/ survival; fig. 7b-d) in the hippocampal GCL and SGZ were stereologically assessed at P74. Our analyses showed no effect of LPS administration on total cell survival (fig. 7a) or neuronal survival (fig. 7b). These results suggest that the reduced neurogenic potential following LPS administration (fig. 5b) is compensated for by enhanced neuronal survival.

Peripheral LPS Effects on Neurogenesis Are Transient

We further asked whether the peripheral LPS-mediated effect on the numbers of type $2 \mathrm{~b}$ and type 3 progenitors was persistent. Reasoning that the lower presence of DCX ${ }^{\text {pos }}$ type $2 \mathrm{~b}$ and type 3 cells in the mature hippocampus would make them amenable to exhaustive counting, we quantified the absolute number of DCX ${ }^{\text {pos }}$ cells in the adult (P74) hippocampal SGZ (fig. 8a-c). No significant difference could be observed between the
LPS and saline groups, highlighting the transient nature of peripheral LPS-induced inhibition of neuronal differentiation.

\section{Discussion}

In this study we investigated the acute, subacute and chronic effects of experimentally induced neonatal peripheral inflammation on the developing hippocampus. Our results show that peripheral LPS stimulation induces an acute expansion of the hippocampal microglia population, which occurs through increased proliferation in the absence of peripheral monocyte infiltration. Further, qRT-PCR analysis of hippocampal gene expression indicates dysregulation of several genes associated with both M1 and M2 microglial phenotypes, a response which persists for at least 14 days. Repetition of these analyses on MACS-isolated microglia from the hippocampus gave results partially supportive of our hypothesis of long-term changes to microglial inflammatory status. We next screened for perturbations of the ongoing neurogenic process in the hippocampal neurogenic niche. Our analyses indicate that neonatal LPS administration transiently reduces neurogenesis 2 weeks after LPS administration in a proliferation-independent manner, specifically affecting the type 3 NPC population. Paradigms tracing the fate of cells born during this period through to P74 indicate that these differentiation deficits are insufficient to reduce the number of mature neurons derived from progenitors entering the cell cycle during this period, leading us to posit that the observed inhibition of neuronal fate commitment is compensated for by enhanced neuronal survival in this model.

Common opinion holds that yolk sac-derived myeloid precursors colonize the developing murine CNS between embryonic days 7 and 7.5 [36], where they proliferate ex- 
tensively during embryonic and early postnatal development, eventually giving rise to mature ramified microglia $[29,37]$. Proliferation is rapidly restricted in the first 2 postnatal weeks [29], with adult microglia displaying low turnover [38] and highly limited replacement by peripheral monocytes under non-pathological conditions [39]. Our observation of increased hippocampal microglial cell number and density $48 \mathrm{~h}$ after LPS administration is broadly in agreement with previous reports studying the effects of peripheral inflammatory stimulation with $E$. coli in neonatal rodents [27], and with LPS in juvenile and adult $[21,24,40]$ rodents. These studies have variously shown increased total numbers of Iba $1^{\text {pos }}$, activated $\left(\mathrm{ED} 1^{\text {pos }}\right.$ or Iba $1^{\text {pos}} /$ morphologically activated) and proliferating (Iba1 $\left.{ }^{\text {pos}} / \mathrm{BrdU}^{\mathrm{pos}}\right)$ microglia in some, or all, hippocampal regions analysed. Whilst our stereological studies did not specifically address microglial activation status, we did observe a greater number of Iba ${ }^{\text {pos }}$ cells exhibiting elongated to rounded cell bodies with thickened processes (fig. 1c, d, 2d, e) consistent with the morphological characteristics of activated microglia [10]. Additionally we found that LPS increased microglial density in P7 animals to a level similar to that observed in salineand LPS-administered P21 and P74 animals. These observations of similar microglial densities in LPS-administered P7, P21 and P74 animals could speculatively suggest that there may be a target or maximum density in the brain and that control of microglial proliferation may be juxtacrine in nature. Indeed microglia express both Notch-1 receptor and its ligands Jagged-1 and Delta-1 [41], and Notch activation induces expression of the Runx1 (Runt-related) transcription factor [42], which in turn inhibits amoeboid microglial progenitor proliferation and facilitates progression from amoeboid precursor to ramified microglia [37]. Having observed an LPS-mediated acute increase in microglial cell density at P7, we asked whether these additional microglia were derived from endogenous microglia/myeloid precursor cell proliferation or peripheral monocyte recruitment. Experiments utilizing $L y s$-EGFP-ki mice, in which myeloid cells generated by definitive but not primitive haematopoiesis express EGFP [31,32], indicated a complete lack of peripheral contribution to the LPS-induced increase in microglia number.

Upon stimulation, microglia assume an 'activated' phenotype which has been associated with inhibition of adult neurogenesis [21, 43]. Enhanced scrutiny of activated microglia allows the distinction of populations with both pro- (M1) and anti-inflammatory (M2) phenotypes [14]. Interestingly, in vitro studies indicate that LPS-acti-

Effects of Systemic Inflammation on the Developing Hippocampus vated microglia (M1) reduce neurogenesis, whereas Il4activated microglia (M2) act to enhance neurogenesis $[15,44]$. We employed qRT-PCR to probe hippocampal expression of genes associated with the M1 (Cd68, Illb, iNOS and Il6) and M2 (Ym1, Cd206, Arg1 and Il10) phenotypes. Our data show regulation of M1 - and M2-related target genes $48 \mathrm{~h}$, and of M1-related genes 2 weeks, after LPS administration. At $48 \mathrm{~h}, \mathrm{Cd} 86$ and $\mathrm{Ym} 1$ are both upregulated, whilst 14 days later $i N O S$ is upregulated and Il6 downregulated. When comparing the temporal regulation of whole hippocampal gene expression in the present study with data generated by $\mathrm{Hu}$ et al. [45], who investigated expression of a larger panel of M1/M2-related genes at numerous time points following transient focal cerebral ischemia in 10- to 12 -week-old mice, we see striking concurrence. Comparison of the 6 genes present in both studies reveals a similar postinjury temporal expression pattern with upregulation of $C d 86$ and $Y m 1$ and no change in iNOS expression $72 \mathrm{~h}$ after middle cerebral artery occlusion, and upregulation of $i N O S$ and no change in Cd86, Ym1 and Arg1 14 days after the injury.

Specific analysis of gene expression in hippocampal microglia 2 weeks after LPS administration supported the lack of regulation of M2 markers at this time point. Interestingly, we observed a relatively large, but insignificant, percentage regulation of the M1 markers iNOS (121.8\%) and Il6 (158.8\%). Whilst it is unwise to draw strong conclusions from insignificant data, we can make two minor inferences from the direction of regulation. First, Il6 is positively regulated in isolated hippocampal microglia, suggesting that another cell type is responsible for the reduced expression of $I l 6$ quantified in samples derived from whole hippocampi. Secondly, microglia-related iNOS expression may contribute to the overall induction of iNOS expression in the hippocampus. Together our data indicate a prolonged and evolving hippocampal inflammatory response to neonatal systemic LPS administration, with regulation of both M1- and M2-associated genes in the acute phase, and regulation of only M1-associated genes at P21.

Neurogenesis is a highly plastic process known to be influenced by negative stimuli such as stress [46] and inflammation $[15,21,43,47]$. In this study, we assessed the main contributors to net neurogenesis, namely proliferation, differentiation and survival, in the hippocampal SGZ and GCL following systemic inflammation in the developing hippocampus. We observed a transient reduction in neuronal commitment (BrdU ${ }^{\text {pos}} / \mathrm{DCX}^{\mathrm{pos}}$ ) 16-23 days after LPS administration, an alteration apparently due to effects on type 3 neuronal precursor cells, which 
occurred in the absence of effects on hippocampal cell proliferation or survival of BrdUpos cells. This finding is in line with previous reports suggesting that inflammation-mediated effects on cell proliferation and survival are, respectively, limited to cells undergoing mitosis either at [23] or immediately following [27] immune challenge. Our failure to detect any deficit in the number of mature granule cells (BrdU ${ }^{\text {pos }} / \mathrm{NeuN}^{\mathrm{pos}}$ ) born in the $\mathrm{P} 22$ P25 period (a time at which we observed reduced neuronal commitment) strongly indicates more effective integration of the remaining immature neurons into the developing hippocampal network. Indeed, under normal conditions, many newborn cells die long before maturing to granule cells $[48,49]$, with survival being linked to network integration and input activity [50]. Thus, the lack of an LPS effect on the absolute number of adult neurons could be due to more efficient network integration and concomitant enhanced survival of the remaining cells.

In conclusion, experimental systemic inflammation occurring during the early postnatal period is transduced to the immature CNS, where it further induces alterations in the developing hippocampal stem cell niche. LPS administration acutely stimulates proliferation of immature microglia, increasing both microglial population size and density, and initiating a prolonged alteration to hippo- campal inflammatory status. These inflammation-mediated changes occur in conjunction with transient inhibition of neuronal fate commitment among type 3 hippocampal NPCs, an alteration which does not appear to affect the number of mature neurons derived from cells born during this period. Such results suggest that whilst capable of initiating lasting changes within the developing hippocampus, LPS administration at the studied time point and dose is not sufficient to overwhelm the abundant plasticity of the developing hippocampus. However, such changes may reduce the organisms' reserve of hippocampal plasticity, enhancing susceptibility to secondary insult and facilitating the onset of later-life pathologies.

\section{Acknowledgements}

This research received financial assistance from the Swedish Medical Research Council (VR 2009-2630, 2012-2992), a government grant to a researcher in Public Health Service at the Sahlgrenska University Hospital (ALFGBG-142881; 137601), European Union grant FP7 (Neurobid; HEALTH-F2-2009-241778), the Leducq Foundation (DSRR_P34404), Åhlén stiftelsen and Wilhelm och Martina Lundgrens stiftelsen. We additionally acknowledge the Centre for Cellular Imaging at the University of Gothenburg for use of their imaging equipment, instruction and support.

\section{References}

1 Brown AS, Begg MD, Gravenstein S, Schaefer CA, Wyatt RJ, Bresnahan M, Babulas VP, Susser ES: Serologic evidence of prenatal influenza in the etiology of schizophrenia. Arch Gen Psychiatry 2004;61:774-780.

$\checkmark 2$ Shi L, Fatemi SH, Sidwell RW, Patterson PH: Maternal influenza infection causes marked behavioral and pharmacological changes in the offspring. J Neurosci 2003;23:297-302.

3 Rantakallio P, Jones P, Moring J, von Wendt L: Association between central nervous system infections during childhood and adult onset schizophrenia and other psychoses: a 28-year follow-up. Int J Epidemiol 1997;26: 837-843.

4 Hornig M, Weissenböck H, Horscroft N, Lipkin WI: An infection-based model of neurodevelopmental damage. Proc Natl Acad Sci USA 1999;96:12102-12107.

5 Gage FH, Kempermann G, Palmer TD, Peterson DA, Ray J: Multipotent progenitor cells in the adult dentate gyrus. J Neurobiol 1998;36: 249-266.

- 6 Eriksson PS, Perfilieva E, Björk-Eriksson T, Alborn AM, Nordborg C, Peterson DA, Gage FH: Neurogenesis in the adult human hippocampus. Nat Med 1998;4:1313-1317.
7 Curtis MA, Kam M, Nannmark U, Anderson MF, Axell MZ, Wikkelso C, Holtås S, van Roon-Mom WM, Björk-Eriksson T, Nordborg C, Frisén J, Dragunow M, Faull RL, Eriksson PS: Human neuroblasts migrate to the olfactory bulb via a lateral ventricular extension. Science 2007;315:1243-1249.

-8 Tremblay ME, Lowery RL, Majewska AK: Microglial interactions with synapses are modulated by visual experience. PLoS Biol 2010; 8:e1000527.

-9 Sierra A, Encinas JM, Deudero JJ, Chancey JH, Enikolopov G, Overstreet-Wadiche LS, Tsirka SE, Maletic-Savatic M: Microglia shape adult hippocampal neurogenesis through apoptosis-coupled phagocytosis. Cell Stem Cell 2010;7:483-495.

10 Kreutzberg GW: Microglia: a sensor for pathological events in the CNS. Trends Neurosci 1996;19:312-318.

$\checkmark 11$ Hanisch UK: Microglia as a source and target of cytokines. Glia 2002;40:140-155.

12 Davalos D, Grutzendler J, Yang G, Kim JV, Zuo Y, Jung S, Littman DR, Dustin ML, Gan WB: ATP mediates rapid microglial response to local brain injury in vivo. Nat Neurosci 2005;8:752-758.
13 Nimmerjahn A, Kirchhoff F, Helmchen F: Resting microglial cells are highly dynamic surveillants of brain parenchyma in vivo. Science 2005;308:1314-1318.

14 Colton CA: Heterogeneity of microglial activation in the innate immune response in the brain. J Neuroimmune Pharmacol 2009;4: 399-418.

15 Butovsky O, Ziv Y, Schwartz A, Landa G, Talpalar AE, Pluchino S, Martino G, Schwartz M: Microglia activated by IL- 4 or IFN- $\gamma$ differentially induce neurogenesis and oligodendrogenesis from adult stem/progenitor cells. Mol Cell Neurosci 2006;31:149-160.

-16 Cacci E, Ajmone-Cat MA, Anelli T, Biagioni S, Minghetti L: In vitro neuronal and glial differentiation from embryonic or adult neural precursor cells are differently affected by chronic or acute activation of microglia. Glia 2008;56:412-425.

17 Streit WJ: Microglia as neuroprotective, immunocompetent cells of the CNS. Glia 2002; 40:133-139.

18 Innamorato NG, Lastres-Becker I, Cuadrado A: Role of microglial redox balance in modulation of neuroinflammation. Curr Opin Neurol 2009;22:308-314. 
-19 Turrin NP, Gayle D, Ilyin SE, Flynn MC, Langhans W, Schwartz GJ, Plata-Salaman CR: Pro-inflammatory and anti-inflammatory cytokine mRNA induction in the periphery and brain following intraperitoneal administration of bacterial lipopolysaccharide. Brain Res Bull 2001;54:443-453.

20 Vallières L, Rivest S: Regulation of the genes encoding interleukin-6, its receptor, and gp130 in the rat brain in response to the immune activator lipopolysaccharide and the proinflammatory cytokine interleukin- $1 \beta$. J Neurochem 1997;69:1668-1683.

21 Monje ML, Toda H, Palmer TD: Inflammatory blockade restores adult hippocampal neurogenesis. Science 2003;302:1760-1765.

22 Eklind S, Hagberg H, Wang X, Sävman K, Leverin $A L$, Hedtjärn M, Mallard C: Effect of lipopolysaccharide on global gene expression in the immature rat brain. Pediatr Res 2006; 60:161-168.

-23 Fujioka H, Akema T: Lipopolysaccharide acutely inhibits proliferation of neural precursor cells in the dentate gyrus in adult rats. Brain Res 2010;1352:35-42.

24 Wu CW, Chen YC, Yu L, Chen HI, Jen CJ, Huang AM, Tsai HJ, Chang YT, Kuo YM: Treadmill exercise counteracts the suppressive effects of peripheral lipopolysaccharide on hippocampal neurogenesis and learning and memory. J Neurochem 2007;103:24712481.

-25 Bilbo SD, Levkoff LH, Mahoney JH, Watkins LR, Rudy JW, Maier SF: Neonatal infection induces memory impairments following an immune challenge in adulthood. Behav Neurosci 2005;119:293-301.

-26 Bilbo SD, Barrientos RM, Eads AS, Northcutt A, Watkins LR, Rudy JW, Maier SF: Early-life infection leads to altered BDNF and IL-1 $\beta$ mRNA expression in rat hippocampus following learning in adulthood. Brain Behav Immun 2008;22:451-455.

27 Bland ST, Beckley JT, Young S, Tsang V, Watkins LR, Maier SF, Bilbo SD: Enduring consequences of early-life infection on glial and neural cell genesis within cognitive regions of the brain. Brain Behav Immun 2010;24:329338.

28 Bayer SA: Development of the hippocampal region in the rat. II. Morphogenesis during embryonic and early postnatal life. J Comp Neurol 1980;190:115-134.
29 Alliot F, Godin I, Pessac B: Microglia derive from progenitors, originating from the yolk sac, and which proliferate in the brain. Brain Res Dev Brain Res 1999;117:145-152.

30 Kronenberg G, Reuter K, Steiner B, Brandt $\mathrm{MD}$, Jessberger S, Yamaguchi M, Kempermann G: Subpopulations of proliferating cells of the adult hippocampus respond differently to physiologic neurogenic stimuli. J Comp Neurol 2003;467:455-463.

31 Faust N, Varas F, Kelly LM, Heck S, Graf T: Insertion of enhanced green fluorescent protein into the lysozyme gene creates mice with green fluorescent granulocytes and macrophages. Blood 2000;96:719-726.

32 Mawhinney LA, Thawer SG, Lu WY, Rooijen N, Weaver LC, Brown A, Dekaban GA: Dif ferential detection and distribution of microglial and hematogenous macrophage populations in the injured spinal cord of lysEGFP-ki transgenic mice. J Neuropathol Exp Neurol 2012;71:180-197.

33 Bohatschek M, Werner A, Raivich G: Systemic LPS injection leads to granulocyte influx into normal and injured brain: effects of ICAM-1 deficiency. Exp Neurol 2001;172: 137-152.

34 Hua LL, Kim MO, Brosnan CF, Lee SC: Modulation of astrocyte inducible nitric oxide synthase and cytokine expression by interferon beta is associated with induction and inhibition of interferon gamma-activated sequence binding activity. J Neurochem 2002;83:11201128.

35 Gruol DL, Nelson TE: Physiological and pathological roles of interleukin-6 in the central nervous system. Mol Neurobiol 1997;15:307339.

36 Ginhoux F, Greter M, Leboeuf M, Nandi S, See P, Gokhan S, Mehler MF, Conway SJ, Ng LG, Stanley ER, Samokhvalov IM, Merad M: Fate mapping analysis reveals that adult microglia derive from primitive macrophages. Science 2010;330:841-845.

37 Zusso M, Methot L, Lo R, Greenhalgh AD, David S, Stifani S: Regulation of postnatal forebrain amoeboid microglial cell proliferation and development by the transcription factor Runx1. J Neurosci 2012;32:1128511298.

38 Lawson LJ, Perry VH, Gordon S: Turnover of resident microglia in the normal adult mouse brain. Neuroscience 1992;48:405-415.

- 39 Ajami B, Bennett JL, Krieger C, Tetzlaff W, Rossi FM: Local self-renewal can sustain CNS microglia maintenance and function throughout adult life. Nat Neurosci 2007;10:15381543 .
40 Diz-Chaves Y, Pernía O, Carrero P, GarciaSegura LM: Prenatal stress causes alterations in the morphology of microglia and the inflammatory response of the hippocampus of adult female mice. J Neuroinflammation 2012;9:71.

41 Cao Q, Lu J, Kaur C, Sivakumar V, Li F, Cheah PS, Dheen ST, Ling EA: Expression of Notch-1 receptor and its ligands Jagged-1 and Delta-1 in amoeboid microglia in postnatal rat brain and murine BV-2 cells. Glia 2008;56:12241237.

42 Burns CE, Traver D, Mayhall E, Shepard JL, Zon LI: Hematopoietic stem cell fate is established by the Notch-Runx pathway. Genes Dev 2005; 19:2331-2342.

43 Ekdahl CT, Claasen JH, Bonde S, Kokaia Z, Lindvall O: Inflammation is detrimental for neurogenesis in adult brain. Proc Natl Acad Sci USA 2003;100:13632-13637.

44 Chhor V, le Charpentier T, Lebon S, Oré MV, Celador I, Josserand J, Degos V, Jacotot E, Hagberg H, Sävman K, Mallard C, Gressens P, Fleiss B: Characterization of phenotype markers and neuronotoxic potential of polarised primary microglia in vitro. Brain Behav Immun 2013;32:70-85.

$45 \mathrm{Hu}$ X, Li P, Guo Y, Wang H, Leak RK, Chen S, Gao Y, Chen J: Microglia/macrophage polarization dynamics reveal novel mechanism of injury expansion after focal cerebral ischemia. Stroke 2012;43:3063-3070.

46 Coe CL, Kramer M, Czéh B, Gould E, Reeves AJ, Kirschbaum C, Fuchs E: Prenatal stress diminishes neurogenesis in the dentate gyrus of juvenile rhesus monkeys. Biol Psychiatry 2003;54:1025-1034.

47 Rolls A, Shechter R, London A, Ziv Y, Ronen A, Levy R, Schwartz M: Toll-like receptors modulate adult hippocampal neurogenesis. Nat Cell Biol 2007;9:1081-1088.

48 Kempermann G, Gast D, Kronenberg G, Yamaguchi M, Gage FH: Early determination and long-term persistence of adult-generated new neurons in the hippocampus of mice. Development 2003;130:391-399.

49 Biebl M, Cooper CM, Winkler J, Kuhn HG: Analysis of neurogenesis and programmed cell death reveals a self-renewing capacity in the adult rat brain. Neurosci Lett 2000;291: $17-20$.

50 Tashiro A, Sandler VM, Toni N, Zhao C, Gage FH: NMDA-receptor-mediated, cell-specific integration of new neurons in adult dentate gyrus. Nature 2006;442:929-933.
Effects of Systemic Inflammation on the Developing Hippocampus
Dev Neurosci 2014;36:119-131 DOI: $10.1159 / 000359950$ 